\title{
Audiovisual Distraction: A Pricking Pain Reduction Modality among Ladies Receiving Intraoral Injections
}

\author{
Munazza Aziz1, Shahbaz Ahmed Jat1, Fazal-ur-Rehman Qazi1, Farah Naz², Prena Moorpani1 and Marina Shah1 \\ ${ }^{1}$ Department of Dentistry, Dr. Ishrat-ul-Ebad Khan Institute of Oral Health Sciences, DUHS, Karachi, Pakistan \\ ${ }^{2}$ Dental Section, Dow International Medical College, Karachi, Pakistan
}

\begin{abstract}
Objective: To determine the effect of audiovisual distraction (AVD) using virtual reality device (bobo VRZ4-VRBOX) on intensity of pricking pain at the intraoral injection site among different age groups in ladies.

Study Design: Experimental study.

Place and Duration of Study: Department of Operative Dentistry, Dr. Ishrat-ul-Ebad Khan Institute of Oral Health Sciences, Dow University of Health Sciences, Karachi, during September 2018 to March 2019.

Methodology: An in-vivo interventional study, using split-mouth technique was conducted in 50 lady patients of sample size of 50, to investigate pricking pain perception during needle insertion. Topical anesthesia (benzocaine gel) was applied on left side (control) for 1 minute without audiovisual distraction (AVD); whereas, on the experimental side (right), similar methodology was followed after topical anesthesia but with AVD via VR-Z4 video eyeglasses after the local anesthesia was administered. Patients' pain perception ratings were measured through visual analog scale (VAS). After profound anesthesia was achieved, restorative treatment was performed under rubber dam isolation.

Results: Audiovisual (AV) device was effective in decreasing the pricking pain sensed by the patients during infiltrate anesthesia; but the score remained within the same pain category. The effect of audiovisual distraction (AVD) using virtual reality device (VRZ4-VRBOX) was statistically insignificant on intensity of pricking pain at the intraoral injection site among different age groups in ladies.

Conclusion: AV device is not dependent on age (21-50 years) in reducing the pricking pain. Pain is effectively reduced after the use of AV device, but this reduction is not statistically significant.
\end{abstract}

Key Words: Audio visual aid, Local anesthetics, Pain perception, Dental procedure anxiety.

How to cite this article: Aziz M, Jat SA, Qazi FUR, Naz F, Moorpani P, Shah M. Audiovisual distraction: A pricking pain reduction modality among ladies receiving intraoral injections. J Coll Physicians Surg Pak 2020; 30(1):4-8.

\section{INTRODUCTION}

Anxiety is an unpleasant emotional and psychological condition to an external threat that includes fear and apprehension of distressed responses. ${ }^{1}$ There are many factors documented, ${ }^{2}$ that cause anxiety out of which major factors are pricking pain and fear caused by the vision of needle called as blenophobia. ${ }^{3}$ Anticipation of pain due to needle prick is most commonly observed in dental procedures. Multiple methods such as use of topical anesthetic agent (e.g. benzocaine), buffering the local anesthetics, warming the local anesthetic agents, and adjusting the pace of the infiltration by lowering the speed of injection are employed to alleviate this pain.

Distraction is a preferential approach used to alter the patient's agitation by disrupting his/her attention away from the main task to gain successful treatment. ${ }^{4}$ There

Correspondence to: Dr. Munazza Aziz, Department of Dentistry, Dr. Ishrat-ul-Ebad Khan Institute of Oral Health Sciences, DUHS, Karachi, Pakistan

E-mail: munazza_aziz24@hotmail.com

Received: May 18, 2019; Revised: October 26,2019;

Accepted: Decemeber 16, 2019 are many ways to distract mind such as, by rubbing the mucosa on the contralateral side, showing documentary video to the subject, non-procedural talks, and playing games on the tablet. ${ }^{5}$ Audiovisual distraction method is the most recent advancement that can be employed in dentistry to reduce anxiety and pain. This method has been used in the pedodontics practice. Agarwal et al.,1 reported that topical anesthesia (i.e. benzocaine) along with AVD was found more effective as compared to the benzocaine alone while giving LA in the pediatric patients. Similar results were found by Chaturvedi et al. ${ }^{6}$ On the contrary, Bentsen et al. reported no hypoalgesic result with the video glasses when painful stimulus was given. ${ }^{7}$ Similar results were found by Al-Halabi et al. which reported that the VR-BOX had no added advantage in reducing pain. ${ }^{8}$

AVD is a prominent technique that can be used in the invasive dental procedures to relieve pain and anxiety. Paedodontic studies show contradictory results and the investigators have vague in the effectiveness of its use.1,5,6 Levine et al. studied the effect of pain perceived in both genders and concluded that females perceived more pain as compared to the males. ${ }^{9}$ 
Till date, no clinical study has been carried out to evaluate the efficacy of this technique on the adult population.

The aim of the study was to evaluate the effect of AVD using virtual reality device (VRZ4-VRBOX) on the intensity of pricking pain at the intraoral injection site among different age groups in lady patients.

\section{METHODOLOGY}

An in-vivo, intervention was conducted in the Department of Operative Dentistry, Dr. Ishrat-ul-Ebad Khan Institute of Oral Health Sciences, Dow University of Health Sciences, Karachi, during September 2018 to March 2019, and was approved by the Institutional Ethical Committee. The sample size for the study was estimated using software Open Epi Version 3. The mean and standard deviation in experimental group was (5.86 $\pm 0.77)^{1}$ and control group was $(7.36 \pm 0.71)^{1}$ with $95 \%$ confidence interval and $80 \%$ power of test, the estimate sample size was 4 subjects in each group. But for the accuracy and generalisability of results, sample size of 50 was taken. The patients were included in the study using non-probability purposive sampling technique.

The selection criteria for participants included lady patients with age group of 21 to 50 years and patients coming for the restorative treatment of maxillary teeth having carious lesion with the symptoms of reversible pulpitis (mild pain or sensitivity that last few seconds after the stimulus was removed) in bilateral maxillary premolars were included.

Patients with systemic disease i.e. diabetes, hypertension, HIV, liver or kidney transplant and with the intellectual disabilities, psychiatric disorders, dental abscess and fistula were excluded from the study. Patients who took any pain killer prior to procedure and the patients having the tooth with pulp necrosis (dead pulp tissue, hence no response on pulp testing) were also excluded from the study.

To determine the efficacy of audiovisual distraction device (VR-Z4) on the intensity of pricking pain, the split mouth approach was used on bilateral maxillary premolar teeth. Before starting the procedure, written consent from all the participants were taken.

Age was stratified into three groups: 21 to 30 years, 31-40 years and 41 to 50 years. In each group, the site of anesthesia was cleaned with the sterile gauze. On the left intraoral side (control), topical anesthesia (dental opahl $20 \%$ benzocaine), followed by maxillary buccal infiltration anesthesia (medicaine - $1.8 \mathrm{ml}$ inj. (lidocaine) with 1:100,000 epinephrine, using 27-G needle), was applied for 1 minute using the following protocol. Area was dried using triple air syringe and topical anesthesia was applied using cotton tipped applicator. Topical anesthesia (dental opahl $20 \%$ benzocaine), was applied for one minute using rubbing motion and left for 30

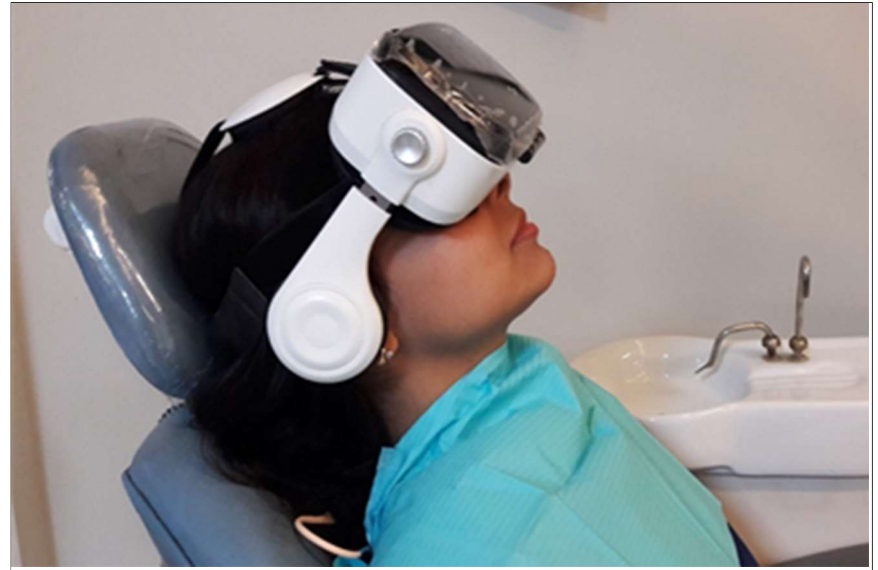

Figure 1: Audiovisual device (VRZ4-VRBOX).

seconds to increase the penetration depth, which is generally recommended to minimise the sensation of pain.10,11 On the right intraoral side (experimental), audiovisual distraction through virtual reality device (bobo VRZ4-VRBOX) was used in which a documentary video (cooking show) of 2 minutes duration was played while the topical anesthesia was applied during the first minute using same protocol as on the left side so that the subjects were fully distracted (Figure 1). During the second minute of the video, maxillary buccal infiltration anesthesia (medicaine - $1.8 \mathrm{ml}$ inj. (lidocaine) with 1:100,000 epinephrine, using $27-G$ needle) was administered.

To indicate the pain perceived on pricking the anesthetic needle, each participant was asked to indicate the pain of prick of anesthetic needle on visual analog scale (VAS). The pain rating score (PRS) of VAS scale consist of 0 to 10 readings in which 0 means no pain, 1 to 2 means mild pain, 3 to 6 means moderate pain, 7 to 9 means severe pain, and 10 means worst possible pain. ${ }^{3}$ The readings were recorded for each participant by principal investigator and is confirmed by the co-investigator, who was blinded to the groups. After profound anesthesia was achieved, restorative treatment was performed under rubber dam isolation.

Statistical descriptive analyses, such as mean and standard deviation of age and the frequencies with percentages of VAS score for qualitative and quantitative variables respectively, were calculated using SPSS version 23. The significance of VAS score among different age groups that is 21 to 30 years, 31 to 40 years and 41 to 50 years, was calculated using Fisher Exact test. The $p$-value of $<0.05$ was considered as significant.

\section{RESULTS}

A total number of 50 adult ladies $(n=50)$ were inducted. Age was stratified into three groups 21 to 30 years, 31-40 years and 41 to 50 years with $19(38 \%), 20(40 \%), 11(22 \%)$ 
Table I: Age-wise stratified analysis of the pain scores among control and experimental group.

\begin{tabular}{|c|c|c|c|c|c|c|}
\hline \multirow{3}{*}{ Groups } & \multicolumn{2}{|c|}{ Responses of control group } & \multirow{2}{*}{\multicolumn{3}{|c|}{$\begin{array}{c}\text { Experimental pain rating scores (PRS) } \\
\text { ' } n \text { ' count }(\%)\end{array}$}} & \multirow[t]{3}{*}{ Pain } \\
\hline & \multirow[t]{2}{*}{ Category } & \multirow[t]{2}{*}{ 'n' count $(\%)$} & & & & \\
\hline & & & No pain & Mild pain & Moderate pain & \\
\hline \multirow[t]{6}{*}{$21-30$ years } & No pain & $1(100 \%)$ & $-(0 \%)$ & $1(100 \%)$ & $-(0 \%)$ & \multirow[t]{6}{*}{0.935} \\
\hline & Mild pain & $8(100 \%)$ & $3(37.5 \%)$ & $5(62.5 \%)$ & $-(0 \%)$ & \\
\hline & Moderate pain & $8(100 \%)$ & $3(37.5 \%)$ & $4(50 \%)$ & $1(12.5 \%)$ & \\
\hline & Severe pain & $1(100 \%)$ & $1(100 \%)$ & $-(0 \%)$ & $-(0 \%)$ & \\
\hline & Worst possible pain & $1(100 \%)$ & $-(0 \%)$ & $1(100 \%)$ & $-(0 \%)$ & \\
\hline & Total 'n' (\%) & $19(100 \%)$ & $7(36.8 \%)$ & $11(57.9 \%)$ & $1(5.3 \%)$ & \\
\hline \multirow[t]{6}{*}{$31-40$ years } & No pain & $2(100 \%)$ & $-(0 \%)$ & $2(100 \%)$ & $-(0 \%)$ & \multirow[t]{6}{*}{0.895} \\
\hline & Mild pain & $8(100 \%)$ & $3(37.5 \%)$ & $3(37.5 \%)$ & $2(25 \%)$ & \\
\hline & Moderate pain & $9(100 \%)$ & $3(33.3 \%)$ & $5(55 \%)$ & $1(11.1 \%)$ & \\
\hline & Severe pain & $0(0 \%)$ & $-(0 \%)$ & $-(0 \%)$ & $-(0 \%)$ & \\
\hline & Worst pain possible & $1(100 \%)$ & $-(0 \%)$ & $1(100 \%)$ & $-(0 \%)$ & \\
\hline & Total 'n' (\%) & $20(100 \%)$ & $6(30 \%)$ & $11(55 \%)$ & $3(15 \%)$ & \\
\hline \multirow[t]{4}{*}{$41-50$ years } & No pain & $1(100 \%)$ & $-(0 \%)$ & $1(100 \%)$ & $-(0 \%)$ & \multirow[t]{4}{*}{0.372} \\
\hline & Mild pain & $6(100 \%)$ & $4(66.7 \%)$ & $2(33.3 \%)$ & $-(0 \%)$ & \\
\hline & Moderate pain & $4(100 \%)$ & $1(25 \%)$ & $3(75 \%)$ & $-(0 \%)$ & \\
\hline & Total (\%) & $11(100 \%)$ & $5(45 \%)$ & $6(54.5 \%)$ & $-(0 \%)$ & \\
\hline
\end{tabular}

participants, respectively. The mean age was $33.22 \pm$ 8.311 years ranging from 21-50 years. In the 21-30 years age group, 8 participants initially had moderate pain score in control group. In the interventional group, out of these 8 participants, only 1 remained with moderate pain rating, while 4 showed mild pain and 3 showed no pain (Table I). Age-wise comparison of the pain scores among control and experimental groups is given in Table I.

Graphical representation of overall comparison of pain rating scores in control and experimental group is mentioned in Figure 2. The effect of audiovisual distraction (AVD) using virtual reality device (bobo VRZ4-VRBOX) was found to be statistically insignificant on intensity of pricking pain perception at the intraoral injection site among different age groups in adult ladies.

\section{DISCUSSION}

The present study showed minor effect of distraction through audio visual aid used on the lady patients undergoing the dental procedures. Anxiety and fear associated with dental treatment is prevalent even in the adults, despite the advancements in the dental care. Fear of needle is the commonest anxiety provoking effect seen in most of the ladies during their dental treatment. 1,12 Anxiety is the fear of staying in a dental office of dental care provider for therapeutic or preventive care that leads to worsening in oral health. 13 Participants in the present study had received $20 \%$ benzocaine gel on the control side, which is a standard procedure, is a fast-acting ester-type anesthetic agent. It has pleasant taste and low level of systemic absorption. Major disadvantage of benzocaine gel is its low bioadhesivity. ${ }^{14}$ The major concern of this study was needle phobia among the adult lady patients, which is the most common factor noted by majority of the anxious patients. ${ }^{15}$ The results of this study illustrated that the pain during needle penetration was less felt after the use of audiovisual aid as compared to the use of topical anesthesia. The current study corresponds with the results of Zengin et al. 16 who investigated the efficacy of music therapy on pain perception in 100 randomly allocated adult patients undergoing the invasive procedure. They used the subjective VAS and found that the pain was reduced with the intervention.

The results of the present study are in line with the split mouth interventional study conducted by Bhadauria et al. ${ }^{17}$ They used pre-cooling agent to distract mind of 33 adult patients to determine its effect during buccal infiltration. Three minutes application of ice was applied on one side of the mouth (in place of audiovisual aid in the present study) and topical anesthesia was applied on the other half. They reported statistically significant results $(p=0.02)$ among the patients. Similar methodology was conducted as in the present study but their limitations were small sample size and also there were vast difference in the patient allocation in the sub-groups according to age i.e. in $>30$ years $(n=5,15.2 \%), 31$ to 60 years $(n=20,60.6 \%)$ and $>60$ years $(n=8,24.2 \%)$. So, the current study was conducted with different distraction aid using similar procedure to provide a costeffective and reliable method of reducing anxiety in adult patients.

In the present study, the pain experienced by only lady participants in all three age groups was assessed, the reason for this was that the ladies are more anxious during dental procedures. Pain, which was initially moderate to severe or even worst in the 21-30 years and 31-40 years age group, were reduced to mild or no pain with the use of AV device. More patients of 41-50 years perceived mild to moderate pain with infiltrate anesthesia after topical anesthetic application; whereas, 


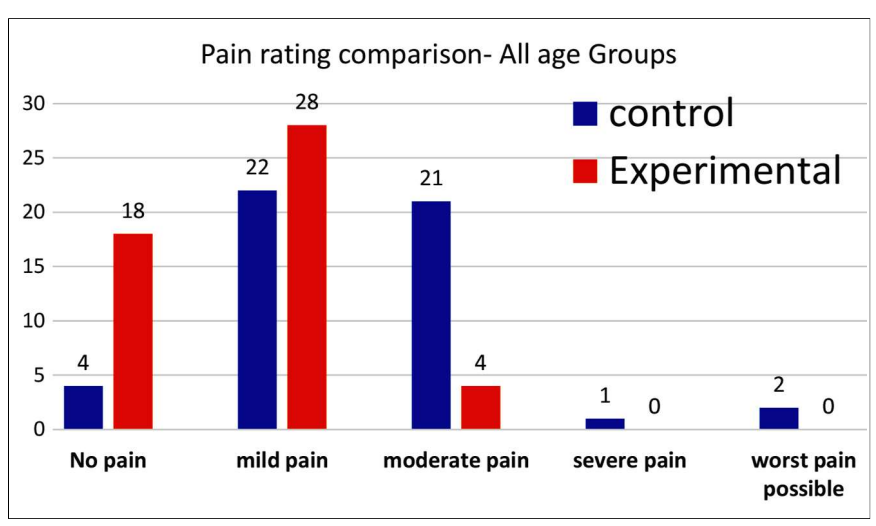

Figure 2: Diagrammatic representation of the overall comparison of pain rating scores in control and experimental group.

on the other side, with the use of AV aids this perception was reduced to mild to no pain. One of the reasons could be because the younger age group patients were more familiar with the new gadgets and showed more interest in the videos played in the device as compared to elderly group who were not showing much attention in the device. Another reason could be because the pain threshold of elderly patients is more as compared to younger ones which can decrease the anxiety level; and hence, the reduced pain perception.

For inter-age group comparison with the use of AV device, the percentage of effect of no-pain was high in 41-50 years age group as compared to the rest of the groups. While mild pain was equal in magnitude in both 21-30 and 31- 40 years age groups but less in the 41-50 years group as shown in the Figure 2. This also augments our intra-group observation suggesting that older age group might have higher pain threshold. This result is similar to study conducted by Bahaduria et al. ${ }^{17}$, who revealed great reduction in the elderly age group.

Multiple studies regarding the use of audiovisual aid have been conducted in dental procedures among pediatric patients. Till date, no dental study has been published on adult patients which used a new technology of distracting mind i.e. audiovisual device during buccal infiltration in the oral cavity. Thereby, the present study has conducted to determine its effect in adult patients. In pediatric patients, the audiovisual device showed contradictory results as reported by Aminabadi et al.18, who reported favourable results i.e. pain was reduced after the intervention, Bentson et al. ${ }^{7}$, who showed relatively unfavourable effect; whereas, Al-Halabi et al.8, showed no additional effect after the use of audiovisual (AV) device during the dental procedures. While among adult patients, one systemic review was published by Hudson BF and Ogden et al.19, regarding the effect of audiovisual aid during non-dental surgical procedures under local anesthesia. It showed that $18 \%$ studies, 20 had beneficial effect from the intervention, $56 \%$ studies $^{21}$, showed no effect, while $25 \%$ studies ${ }^{22}$, showed inconclusive results.
The limitation of this study was that the participants were not equally distributed in each age group and randomisation was not incorporated. Strength of the study was the use of split mouth design, which eliminates all the patients' individual perception, intraoral environment, and teeth specific bias.

\section{CONCLUSION}

Audiovisual (AV) device was found effective in decreasing the pricking pain sensed by the patients during infiltrate anesthesia, but the score remained within the same pain category. The results were, however, statistically insignificant among the control and experimental groups in different age ranges. AV device is not dependent on age (21-50 years) in reducing the pricking pain. The pain is effectively reduced after the use of AV device, but this reduction of pain is not statistically significant.

\section{ETHICAL APPROVAL:}

Ethical approval from Institutional Review Board (IRB) of Dow University of Health Sciences (DUHS) was obtained prior to initiation of the research work.

\section{PATIENTS' CONSENT:}

Informed consents were obtained from all participants to publish the data concerning this case.

\section{CONFLICT OF INTEREST:}

Authors declared no conflict of interest.

\section{AUTHORS' CONTRIBUTION:}

MA: Conception and design of the work, and the acquisition, analysis, and interpretation of the data for the work and agreement to be accountable for all aspects of the work in ensuring that questions related to the accuracy or integrity of any part of the work were appro-priately investigated and resolved.

SA: Drafting the work or revising it critically for important intellectual content

FUR: Final approval of the version to be published.

FN: Drafting the work.

PM: Designing of the work.

MS: Interpretation of data for the work.

\section{REFERENCES}

1. Agarwal N, Dhawan J, Kumar D, Anand A, Tangri K. Effectiveness of two topical anaesthetic agents used along with audio visual aids in paediatric dental patients. J Clin Diagn Res 2017; 11:ZC80.

2. Abanto J, Vidigal EA, Carvalho TS, Sá SN, Bönecker M. Factors for determining dental anxiety in preschool children with severe dental caries. Braz Oral Res 2017; 31: e13.

3. Ghaderi F, Banakar S, Rostami S. Effect of pre-cooling injection site on pain perception in pediatric dentistry: A randomized clinical trial. Dent Res J (Isfahan) 2013; 10:790-4.

4. Al-Namankany A, Petrie A, Ashley P. Video modelling for reducing anxiety related to the use of nasal masks place it for 
inhalation sedation: A randomised clinical trial. Eur Arch Paediatr Dent 2015; 16:13-8.

5. Ram D, Shapira J, Holan G, Magora F, Cohen S, Davidovich E. Audiovisual video eyeglass distraction during dental treatment in children. Quintessence Int 2010; 41:673-9.

6. Chaturvedi S, Walimbe H, Karekar P, Nalawade H, Nankar M, Nene K. Comparative evaluation of anxiety level during the conventional dental procedures with and without audiovisual distraction eyeglasses in pediatric dental patients. J Int Oral Health 2016; 8:1016-22.

7. Bentsen B, Wenzel A, Svensson P. Comparison of the effect of video glasses and nitrous oxide analgesia on the perceived intensity of pain and unpleasantness evoked by dental scaling. Eur J Pain 2003; 7:49-53.

8. Al-Halabi MN, Bshara N, AINerabieah Z. Effectiveness of audiovisual distraction using virtual reality eyeglasses versus tablet device in child behavioral management during inferior alveolar nerve block. Anaesth Pain \& Intensive Care 2018; 22:55-61.

9. Levine FM, De Simone LL. The effects of experimenter gender on pain report in male and female subjects. Pain 1991; 44:69-72.

10. Deepika A, Chandrasekhar Rao R, Vinay C, Uloopi K, Rao VV. Effectiveness of two flavored topical anesthetic agents in reducing injection pain in children a comparative study. $J$ Clin Pediatr Dent 2012; 37:15-8.

11. Ram D, Peretz B. Reactions of children to maxillary infiltration and mandibular block injections. Pediatr Dent 2001; 23:343-6.

12. Mohammed RB, Lalithamma T, Varma DM, Sudhakar KNV, Srinivas B, Krishnamraju PV, et al. Prevalence of dental anxiety and its relation to age and gender in coastal Andhra (Visakhapatnam) population India. J Nat Sci Biol Med 2014; 5:409.

13. Wahid U, Amin M, Choudhry Z, Ahmed MA. Dental anxiety level of patients presenting to operative dentistry department. Pak Oral Dent J 2015; 35:675.
14. Leyda AM, Llena C. Comparation of the eutectic mixture of lidocaine/prilocain versus benzocaine gel in children. Open $J$ Stomatol 2011; 1:84-91.

15. Al-Khotani A, Bello LAa, Christidis N. Effects of audiovisual distraction on children's behaviour during dental treatment: $\mathrm{A}$ randomized controlled clinical trial. Acta Odontol Scand 2016; 74:494-501

16. Zengin S, Kabul S, AI B, Sarcan E, Dogan M, Yildirim C. Effects of music therapy on pain and anxiety in patients undergoing port catheter placement procedure. Complement Ther Med 2013; 21:689-96.

17. Bhadauria US, Dasar PL, Sandesh N, Mishra P, Godha S. Effect of injection site pre-cooling on pain perception in patients attending a dental camp at life line express: A split mouth interventional study. Clujul Med 2017; 90:220-5.

18. Aminabadi NA, Erfanparast L, Sohrabi A, Oskouei SG, Naghili A. The impact of virtual reality distraction on pain and anxiety during dental treatment in 4-6 year old children: A randomized controlled clinical trial. J Dent Res Dent Clin Dent Prospects 2012; 6:117-24.

19. Hudson BF, Ogden J. Exploring the impact of intraoperative interventions for pain and anxiety management during local anesthetic surgery: A systematic review and meta-analysis. $J$ Perianesth Nurs 2016; 31:118-33.

20. Mok E, Wong KY. Effects of music on patient anxiety. AORN J 2003; 77:396-7.

21. Drahota A, Galloway E, Stores R, Ward D, Severs M, Dean T. Audiovisual distraction as an adjunct to pain and anxiety relief during minor surgery. Foot (Edinb) 2008; 18:211-9.

22. Jiménez-Jiménez $M$, García-Escalona A, Martín-López A, De Vera-Vera R, De Haro J. Intraoperative stress and anxiety reduction with music therapy: A controlled randomized clinical trial of efficacy and safety. J Vasc Nurs 2013; 31:101-6. 